\title{
Músicas populares, cognición, afectos e interpelación. Un abordaje socio-semiótico
}

Claudio F. Díaz

Centro de Investigaciones María Saleme de Bournichón (CIFFYH - UNC) Instituto de Humanidades (UNC - CONICET), Córdoba, Argentina

claudiofdiaz@hotmail.com.ar

María de los Ángeles Montes

Instituto de Humanidades (UNC - CONICET), Córdoba, Argentina

montes.m.angeles@gmail.com

Recepción: marzo 2020.

Aceptación: junio 2020.

\section{Resumen}

En los últimos años el campo de las humanidades ha renovado su interés por la dimensión afectiva de los fenómenos sociales, en lo que se ha dado en llamar el giro afectivo. Entre estos fenómenos, la producción y recepción de músicas populares es, sin lugar a dudas, un campo de interés particular. Las músicas impactan en lo afectivo y, al mismo tiempo, las emociones y los sentimientos son un tópico recurrente en gran parte de las canciones. De modo que los modelos teóricos que reponen la importancia de lo afectivo son especialmente interesantes para los estudios sobre las músicas populares. Sin embargo, notamos que algunas de esas propuestas, en su afán por ponderar lo afectivo, terminan por reproducir una lógica dualista que separa lo que conciben como corporal, afectivo y no representacional de lo que entienden por mental, cognitivo y discursivo. Proponemos, en cambio, un enfoque que entiende la dimensión afectiva como parte de cualquier proceso cognitivo y sostenemos que una perspectiva sociodiscursiva brinda valiosas herramientas para la comprensión de esa dimensión en las músicas populares, incluyendo la capacidad que las mismas tienen para interpelar a determinados públicos y contribuir a la construcción de identidades.

Palabras clave: músicas populares, emociones, cognición, discurso, giro afectivo 


\title{
Músicas populares, cognição, afetos e interpelação. Uma abordagem sócio-semiótica
}

\section{Resumo}

Nos últimos anos, o campo das humanidades tem renovado seu interesse pela dimensão afetiva dos fenômenos sociais, no que foi denominado virada afetiva. Entre esses fenômenos, a produção e recepção de músicas populares constituem-se, sem dúvida, como um campo de interesse particular. As músicas impactam no afetivo e, ao mesmo tempo, emoções e sentimentos são um tópico recorrente em grande parte das canções. Dessa maneira, as perspectivas teóricas que reposicionam a importância do afetivo são especialmente interessantes para os estudos sobre as músicas populares. No entanto, notamos que algumas dessas propostas, no afã de considerar o afetivo, acabam reproduzindo uma lógica dualista que separa aquilo que concebem como corporal, afetivo e não representacional daquilo que consideram como mental, cognitivo e discursivo. Propomos, em contrapartida, um enfoque que entende a dimensão afetiva como parte de qualquer processo cognitivo e sustentamos que uma perspectiva sociodiscursiva fornece valiosas ferramentas para a compreensão dessa dimensão nas músicas populares, incluindo a capacidade que elas têm de interpelar determinados públicos e contribuir para a construção de identidades.

Palavras chave: músicas populares, emoções, cognição, discurso, virada afetiva

\section{Popular Music, Cognition, Affects and Interpellation. A Socio-semiotic Approach}

\begin{abstract}
In recent years, the field of humanities has renewed its interest in the affective dimension of social phenomena, in what has been called the affective turn. Among these phenomena, the production and reception of popular music is undoubtedly a particular field of interest. Music has an impact on the affective sphere and, at the same time, emotions and feelings are a recurring topic in many songs. Therefore, theoretical models that reinstate the importance of the affective domain are especially interesting when it comes to popular music studies. However, it is worth mentioning that some of these proposals, in their eagerness to ponder the affects, end up reproducing a dualistic logic that separates what they conceive as
\end{abstract}


corporal, affective and non-representational from what they understand as mental, cognitive and discursive. Instead, we propose an approach that understands the affective dimension as part of any cognitive process, and we maintain that a socio-discursive perspective provides valuable tools for understanding that dimension in popular music, including the ability that they have to challenge certain audiences, and contribute to the construction of identities.

Keywords: Popular music, emotions, cognition, discourse, affective turn

\section{Introducción}

En las aproximaciones analíticas a la música, en particular a las músicas populares, la dimensión emotivo/afectiva de las mismas siempre ha sido al mismo tiempo objeto de interés y fuente de problemas. Por otra parte, la reflexión sobre la capacidad de la música para expresar emociones o para generar respuestas emotivas, ha estado fuertemente marcada por el pensamiento más general sobre lo emocional/afectivo y su relativa importancia en la vida social.

En los últimos años, un conjunto de trabajos del campo de las humanidades y las ciencias sociales han propuesto un cambio respecto a enfoques que habían sido predominantes; un cambio que supone una marcada acentuación de lo afectivo/emocional como parte de los modelos explicativos sobre diferentes prácticas sociales. Este cambio de enfoque ha sido designado con el nombre de "giro afectivo" (affective turn), de forma análoga a transformaciones anteriores como el "giro lingüístico" o el "giro decolonial".

Según señala Leonor Arfuch (2016, p. 248), en cierta medida el "giro afectivo" ha sido una suerte de reacción al "giro textual", a la primacía de lo discursivo en olvido del cuerpo y de las emociones y a ciertos abusos de algunos usos de la noción de discurso. Pero más allá de esas tensiones teóricas, también se trata de un "aire de época" que no resulta ajeno a los cambios societales de los últimos años. En sus términos, viviríamos en una sociedad afectiva, en la que predomina lo subjetivo, el culto a la intimidad, y esa emocionalidad habría permeado la esfera pública, incluyendo la política. Según Lara y Enciso, el "giro afectivo" se ha definido principalmente por dos urgencias teóricas: el interés en la emocionalización de la vida pública, y el esfuerzo por reconfigurar la producción de conocimiento encaminado a profundizar en dicha emocionalización (2013, p. 101). 
Ese interés en lo emocional recoge a la vez diferentes fuentes teóricas de las que nos interesa señalar dos. Por una parte, fuentes filosóficas que abrevan principalmente en la lectura que hace Deleuze de las concepciones spinozianas del afecto como capacidad del cuerpo de afectar y ser afectado. Por otro lado, ciertas lecturas de la afectividad en diálogo con las neurociencias. Por muy diferentes que parezcan esas fuentes, tienen algunos aspectos en común que nos interesa resaltar.

En primer lugar, el afecto se concibe como previo a toda intencionalidad, a toda razón e incluso a toda significación. Serían fuerzas e intensidades que influyen en nuestros pensamientos y acciones, pero tienen un carácter pre-subjetivo. En términos de Arfuch se piensa el afecto como no cognitivo "que sólo sobrevendría después, en un escaso margen temporal- y que se expresa, por ejemplo, según el clásico paradigma de Tomkins-Ekman en unos 6 o 9 afectos básicos y biológicos: interés/excitación; disfrute/alegría; sorpresa/susto; disgusto/angustia; indignación/ira; miedo/terror; vergüenza/humillación; repugnancia/repulsión -el segundo término evoca el grado mayor de intensidad-" (2016, p. 249).

En segundo lugar, se privilegia el cuerpo como lugar de efectuación de esa potencia que es la cualidad de afectar y ser afectado. En ese sentido los afectos son pre-personales, no-conscientes y no pueden realizarse plenamente en el lenguaje. Se vincularían más bien a cambios corporales relacionados con el paso de un estado experiencial a otro. Según Vila (2017) esto puede verse en conceptos muy difíciles de definir, como los de "carisma", "aura" o "presencia”. Estas nociones, dice Vila, generalmente se refieren a una cualidad indefinible de personas o cosas que se sienten en lugar de verse, que se experimentan en la relación entre cuerpos, pero que están por debajo del umbral del lenguaje articulado (2017, p. 27).

Si bien esta acentuación y esta insistencia son muy sugerentes, en realidad, si se plantea en estos términos, el afecto (entendido como esta capacidad de los cuerpos de afectar y ser afectados) quedaría más allá del alcance de la sociología y de la semiótica en tanto nombraría un conjunto de fenómenos pre-sociales y pre-semióticos. Tal vez por eso, según señalan Lara y Enciso (2013) ha tomado fuerza un debate terminológico en el intento de establecer una relación entre los afectos, los sentimientos y las emociones. Aunque todavía no hay consensos terminológicos, las emociones y los sentimientos serían fenómenos de carácter subjetivo, y por lo tanto mediados por lo social y por el sentido. Es decir, sentimientos y emociones constituirían contenidos subjetivos que de algún modo le dan forma a lo afectivo en tanto capacidad corporal de afectar y ser afectado. Las 
relaciones entre esos niveles, según destaca Vila siguiendo a Anderson, no serían estancas ni lineales, sino que están imbricados uno en el otro, generando la posibilidad de pensamientos imbuidos de afecto y de afectos imbuidos de pensamiento (2017, p. 29).

Si se piensa en estos términos, la dimensión afectiva/emotiva de las prácticas sociales adquiere sumo interés para las ciencias sociales, en tanto ayudaría a construir modelos explicativos más complejos para las mismas. Y entre esas prácticas nos interesan particularmente las músicas populares entendidas como producciones discursivas, esto es considerando que forman parte de la red social de producción del sentido. ¿En qué medida la incorporación de la dimensión afectiva/emotiva puede mejorar nuestra comprensión de las músicas populares? ${ }^{1}$

En efecto, en los diversos modelos teóricos que se han construido para intentar dar cuenta del "sentido" de los objetos llamados estéticos, siempre se ha tenido en cuenta la capacidad que los mismos tienen de conmover, de producir una respuesta emotiva que claramente no se reduce a sus significados explícitos. Y esto es particularmente importante en las distintas músicas por su reconocida capacidad evocadora. Tal vez por eso el énfasis en lo afectivo viene a cuestionar modelos de análisis que exageraron los aspectos textuales (ya sea en cuanto al análisis de letras o de partituras) derivados en gran medida del estructuralismo. Ahora bien, en algunas miradas suele establecerse una distinción exagerada entre lo afectivo/ emotivo y los aspectos que se designan, sin mayores distinciones, como "representativos", "cognitivos", "sígnicos” o incluso "conscientes”. A esos aspectos se le oponen observaciones sobre la capacidad de las músicas de afectar "corporalmente", "visceralmente", sobre su capacidad de "movilizar", de "sintonizar" afectivamente a los asistentes a un evento, mediante la circulación de "energías". En esas miradas se insiste en preguntarse no tanto por lo que la música "significa", sino por lo que la música "hace" (Vila, 2017, p. 53).

En este trabajo nos proponemos un abordaje alternativo que recupera tradiciones teóricas un tanto olvidadas en el marco de esta acentuación de la afectividad y que sin embargo pueden ser aportes importantes para pensar el aspecto afectivo de las músicas populares. Un abordaje que principalmente intenta repensar esa oposición demasiado marcada entre lo "emotivo" y lo "representativo".

\footnotetext{
${ }^{1}$ En el próximo apartado justificaremos con más detalle nuestra propuesta de entender las músicas populares como prácticas discursivas.
} 
Ilustraremos nuestras reflexiones a partir de dos ejemplos, no con la intención de presentar un análisis detallado, sino tan sólo de apoyar las conceptualizaciones que presentamos. En primer lugar, tomaremos una canción de cuarteto cordobés, convertida en éxito por Carlos “La Mona” Jiménez en los años 80 y reeditada por muchos cuarteteros desde entonces, entre ellos Ulises Bueno ${ }^{2}$. Se trata de "Amor de compra y venta", una canción que es hoy un clásico cuartetero. En segundo lugar, consideraremos el tema "Olvídame y pega la vuelta" que en 1982 lanzara a la fama al Dúo Pimpinela, convirtiéndose en la más conocida de las "canciones de pelea" que lo caracterizan. ${ }^{3}$

\section{Las emociones como hechos sociales}

Partiremos de una afirmación: se puede abordar la dimensión afectiva/ emotiva en las músicas populares sin necesidad de renunciar a estudiarlas como producciones discursivas. Para ello es necesario, antes que nada, despejar dos equívocos: En primer lugar, hablar de un enfoque discursivo no implica hablar de un enfoque textual, y mucho menos reducir el sentido de las canciones a lo que dicen sus letras. Si recuperamos la ya clásica definición veroniana diremos que discurso es toda "configuración espaciotemporal de sentido", cualquiera sea su soporte material: texto, imagen, o el cuerpo mismo (Verón, 1996, p. 127). Las canciones populares, entonces, pueden pensarse como producciones discursivas que se caracterizan por su complejidad semiótica: la letra, la música, las mediaciones técnicas de su producción y circulación, y todos los aspectos performáticos que se derivan de la interpretación, interactúan de diversas maneras para producir sentido. Abordar las canciones desde un punto de vista discursivo no significa, entonces, trabajar sólo con las letras y las partituras, sino considerar todo ese conjunto significante. Pero, además, un abordaje propiamente discursivo requiere poner en relación ese conjunto significante con sus condiciones sociales de producción y recepción. Si se pueden pensar las músicas populares como discursos es porque son parte (y una muy importante en las sociedades contemporáneas) de la producción social del sentido, esto es, de la semiosis social.

\footnotetext{
${ }^{2}$ La versión que analizaremos en este trabajo es la de una presentación en vivo de Ulises Bueno en 2012, que puede visualizarse en el siguiente link: https://www.youtube.com/ watch?v=zvquHrZRXBI. La letra puede consultarse en: https://www.cmtv.com.ar/discos_letras/ letra.php?bnid=1535\&banda=La_Mona_Jimenez\&DS_DS=3219\&tmid=39375\&tema=AMOR_DE_ COMPRA_Y_VENTA

${ }^{3}$ La versión que analizaremos en este trabajo puede consultarse en el siguiente link: https://www. youtube.com/watch?v=fOHrY0jV6Hg
} 
En segundo lugar, hablar de la semiosis social no implica de ninguna manera referirse a procesos que son externos o ajenos a lo corporal, y mucho menos pensar la significación solamente en relación a procesos cognitivos explícitos, conscientes o racionales. En términos de Verón "el mínimo actoen-sociedad de un individuo supone un encuadre cognitivo socializado, así como una estructuración socializada de las pulsiones" (1996, p. 126). La noción de "pulsión" referida a los impulsos inconscientes, la traemos a colación para señalar que también la vida afectiva/emocional está atravesada por la semiosis, es decir, por lo social.

Podemos ir más lejos. Hay toda una tradición de estudios de la sociología del cuerpo y las emociones que hunde sus raíces en trabajos ya clásicos como los de Norbert Elías, Pierre Bourdieu o Irving Goffman, por citar sólo algunos. Basándonos en esa tradición podemos afirmar que más allá de su funcionamiento biológico, el cuerpo mismo es socialmente modelado, y lo mismo ocurre con las emociones. Esta afirmación implica varias consecuencias:

a) Sin negar lo afectivo en tanto capacidad del cuerpo para afectar y ser afectado (capacidad de sentir dolor, placer, sorpresa, etc.) lo propiamente emocional, si bien arraiga en ese nivel, parte de un sistema simbólico que le da sentido a esa afectación primera. Obviamente, esta afirmación implica que el "sentido" está lejos de reducirse a lo "racional" o, incluso, al lenguaje articulado.

b) las emociones, en tanto hechos sociales, nacen de la interacción con los demás y con el mundo. Las situaciones, los objetos, el contacto con los otros, nos afectan, pero no de un modo automático. Lo propiamente emocional, según Le Breton (1998, p. 106), parte de una evaluación de la situación, aunque sea instantánea y provisoria. Y esa evaluación depende de todo un repertorio cultural, o dicho en nuestros términos, de la semiosis social. Si bien las emociones disparan respuestas corporales a veces incontrolables (el sonrojo ante la vergüenza, por ejemplo), también es cierto que el hecho de sentir vergüenza ante determinado estímulo está mediado por la cultura.

c) Las emociones se expresan a través de respuestas corporales que no siempre se pueden controlar y a través de toda una gestualidad. De ese modo el estado emocional se transmite y puede ser interpretado por los demás. Pero también es cierto que la expresión de las emociones está socialmente regulada. Y esa regulación establece qué emociones se pueden o no expresar, y de qué manera, según la clase, el género, el status, la edad, 
la etnia, etc. No cualquiera puede mostrar cualquier emoción, ni puede hacerlo de cualquier manera. Y, al contrario, según su posición social y su trayectoria, los sujetos están "obligados" a mostrar ciertas emociones y de un modo específico. Es decir, existe una axiología social de la emoción que los sujetos internalizan. Los trabajos de Norbert Elías (2011) nos muestran hasta qué punto los procesos de coacción y autocoacción han dado lugar a cambios profundos en la sensibilidad y en el sistema de reglas para la expresión de la emoción. Irving Goffman (1997) por su parte, ha mostrado hasta qué punto el control de la expresión de las emociones forma parte de la presentación valorada de sí en el complejo juego de las interacciones sociales. A su vez, Le Breton (1998) ha llamado la atención sobre la paradoja del actor (podríamos considerar bajo esta óptica las interpretaciones de los músicos populares) que aprende a expresar las emociones con su gestualidad, con el uso de la voz y de elementos escenográficos, logrando afectar a los espectadores, pero sin sentir necesariamente la emoción que está expresando. Entonces, que la respuesta emocional pueda escapar al control consciente de los sujetos afectados no avala la tesis de que la reacción fisiológica no esté mediada socialmente.

d) Las emociones también se dicen. Y en el caso de la canción popular se dicen con toda su complejidad semiótica. Existen ciertas codificaciones más o menos laxas que vinculan ciertos ritmos, géneros, orquestaciones, tímbricas instrumentales, etc. con ciertos estados emocionales. Insistimos en su laxitud puesto que si bien algunas de estas convenciones arraigan en la materialidad física de los sonidos y la manera en que afectan al cuerpo (intensidad del sonido, cantidad de sonidos en un lapso de tiempo, etc.) lo cierto es que los mismos sonidos pueden producir respuestas emocionales muy distintas en diferentes grupos sociales. Pero, además, en la lírica de la canción popular (con todas las diferencias entre géneros y tradiciones) se ha desarrollado todo un lenguaje de la pasión. Por ejemplo, en el trabajo compilado junto a Martha Tupinambá de Ulhoa sobre la "canción romántica", Simone Luci Pereira muestra la existencia de una matriz "melodramática" en ese tipo de canciones que constituye una "estandarización de las formas de sentir, de pensar, de expresarse en sonidos, voces, formas de bailar, de adjetivar y usar el cuerpo, los acordes y las letras"4 (2016, p. 26). Según el viejo y ya clásico estudio de Denis De Rougemont (1959) esa "retórica de la pasión" propia de lo que se ha llamado "amor romántico" (Giddens, 2008) tiene raíces antiguas que pueden rastrearse hasta la poesía medieval del amor cortés.

\footnotetext{
${ }^{4}$ En su idioma original: "estandartização de maneiras de sentir, de pensar, de se expressar em sons, vozes, formas de dançar, de adjetivar e usar o corpo, acordes e líricas”.
} 
e) Si los distintos sujetos y grupos desarrollan respuestas emotivas diferentes ante las mismas músicas es porque existen lo que Le Breton (2009, pp. 142-150) ha llamado comunidades o culturas afectivas. Es decir, conjuntos de sujetos que comparten los mismos (o al menos similares) repertorios culturales que regulan la emoción.

f) Las culturas afectivas son parte de las identidades sociales. Pero es importante despejar otro equívoco. En términos sociológicos las identidades no son esencias, no son unívocas y no son inmutables. En ese sentido desde hace algunos años la teoría social ha retomado el concepto de "identidades narrativas" desarrollado por Paul Ricoeur (1996) para mostrar la inestabilidad de las identidades, que necesitan permanentemente de una narración que establezca la frontera nosotros/otros y la arraigue en una historia. En la actualidad se ha cuestionado que esa idea todavía implica una cierta unicidad que no deja ver la necesaria heterogeneidad de las identidades en la medida en que la trayectoria social de un sujeto siempre implica diversidad de posiciones en sistemas de relaciones distintos. Por eso algunos autores hablan de una "interseccionalidad" de las prácticas afectivas que permiten que en una situación dada se desplieguen diversos repertorios culturales vinculados a las diferentes posiciones en la trayectoria de los sujetos. Vila y Molinero (2017) hablan de diferentes "articulaciones identitarias" que se despliegan, como en una coreografía, según cómo se desarrolle la relación con los otros en un evento determinado. Estos conceptos son interesantes porque proveen hipótesis plausibles para explicar cómo ocurren esas "sintonizaciones afectivas", por ejemplo, en un recital, y refuerzan la idea de Simon Frith (2003) según la cual las prácticas musicales no sólo expresan identidades, sino que contribuyen de un modo decisivo a producirlas. Planteadas así las cosas, una perspectiva sociodiscursiva sobre los afectos y las emociones nos permite abordar tres conjuntos de problemas que, si bien se encuentran relacionados entre sí, conviene discriminar y encarar por separado.

Por una parte, el modo como lo afectivo cobra cuerpo en los enunciados concretos, es decir, en las canciones, las performances escénicas, los discos, etc. Esto a su vez, y en un segundo nivel de análisis, posibilita analizar cómo esa construcción de lo afectivo forma parte de una estrategia de construcción valorada del propio enunciador. Por otra parte, el análisis de la dimensión afectiva a nivel del enunciado también permite reflexionar acerca del rol de las músicas populares en la reproducción de una economía de la pasión que es constituida por, y constituyente de, relaciones de poder. Por último, también es posible reflexionar acerca del modo como estos enunciados son capaces de interpelar a ciertos sujetos, afectándolos 
emocionalmente. Dicho en otros términos, es posible y necesario incluir la dimensión afectivo/emocional en el análisis de los dispositivos de enunciación en la canción popular.

Observemos brevemente nuestros ejemplos a la luz de estas reflexiones. En el caso de la versión de “Olvídame y pega la vuelta”, del Dúo Pimpinela, el efecto emocional más marcado es la empatía del público (principalmente femenino) con la mujer que rechaza a su ex pareja que quiere volver después de haberla engañado. Pero no sólo es empatía, también se comparte la ira que el personaje despliega mediante la voz, los giros melódicos, el contraste entre el estribillo y las estrofas, y la gestualidad en escena. Sin dudas ese conjunto de elementos afecta a los espectadores, pero la corriente emotiva (empatía + ira) está socialmente mediada. No se trata de una relación espontánea y presocial. La corriente emotiva sólo se entiende en relación con la historia que se está contando, con el complejo sistema de interacciones que se desarrolla en escena y con las identidades sociales de los sujetos representados. Pero también supone un saber (y una experiencia) que los espectadores y los artistas comparten acerca de la posición subordinada de las mujeres en las relaciones de género, del modelo de pareja patriarcal y monogámico, del amor romántico como modelo afectivo dominante, de las convenciones de la música melódica/romántica y de cierto empoderamiento de las mujeres que se viene gestando desde hace varias generaciones y del cual la canción parecería dar testimonio. La capacidad del tema para afectar emocionalmente supone todas esas mediaciones sociales.

Lo mismo ocurre en el caso de "Amor de compra y venta", donde el público comprende y en parte comparte el dolor que el cantante busca proyectar gracias a que pertenecen a una misma cultura afectiva. Ese dolor por no poder dejar de amar a una mujer que alquila su cuerpo a otros, los celos que le despierta el pensar lo que hace con ellos, la impotencia que genera no poder poseerla de manera exclusiva, son todos afectos que sólo pueden comprenderse en el marco de una sociedad en la que el amor es concebido como un sentimiento personal (independiente de la correspondencia del otro), que involucra cariño, deseo sexual y un proyecto de conformación de pareja con exclusividad afectiva y sexual (especialmente de las mujeres). Y donde el mandato de masculinidad es un mandato de poder (Segato, 2003), de modo tal que las infidelidades femeninas (y la impotencia por no poder dejar de amar a pesar de ellas), suponen una herida difícil de sanar para la virilidad masculina. Solamente en ese marco puede comprenderse tanto dolor por la actividad laboral 
de la mujer amada. Solamente a partir de esas creencias, que son previas al momento de la escucha, la comunidad de intérpretes puede ponerse en la piel del enunciador y acompañarlo en el sentimiento.

En ese gesto de acompañamiento por parte del público se produce un sentimiento de comunión que actualiza vínculos identitarios y que tampoco pueden comprenderse si no es en el marco de una comunidad afectiva particular. Ulises ofrece el micrófono para que el público complete con él una canción que es ya un himno del cuarteto cordobés. Lo hace, como lo hace también Carlos Jiménez en cada presentación, ${ }^{5}$ y el público cuartetero se pliega a algo que ya tiene rasgos de ritualidad. Cantar a gritos, en el baile, "Amor de compra y venta", permite sentirse en un nosotros cuartetero. Esa corriente afectiva de identificación y comunión tampoco puede comprenderse por fuera de la historia compartida por esa comunidad particular.

\section{Semiótica de las pasiones, afectividad y narrativa en las letras de las canciones}

Una disciplina que ha reflexionado muy sistemáticamente acerca de la dimensión afectiva de los signos es, sin lugar a dudas, la Semiótica. Sin embargo, lo ha hecho desde dos vertientes teóricas distintas, cada una de las cuales comprende de manera diferente lo afectivo y la producción de sentido misma. En este apartado nos ocuparemos de la semiótica europea, que desarrolló reflexiones teóricas y herramientas analíticas de gran interés para nuestro objeto. Bajo la etiqueta de semiótica de las pasiones, se agrupan diferentes trabajos que abordan el lugar que lo pasional ocupa en los esquemas narrativos (Greimas y Fontanille, 1994; Fabbri, 2000).

Como toda la semiótica estructuralista, parte del supuesto de que el significado es inmanente al texto, de modo tal que bastaría con analizar los textos para dar cuenta de los significados que contienen, y toma al sistema lingüístico como modelo de sistema semiótico. Este paradigma, que dominó la semiótica occidental desde su nacimiento hasta finales del siglo XX, fue tan popular primero, como cuestionado después. Sus modelos de análisis y buena parte de sus presupuestos teóricos fascinaron a muchos pensadores que los replicaron en otras disciplinas, trasladando a esos otros campos de conocimiento sus desaciertos y limitaciones. Y tanto se

\footnotetext{
${ }^{5}$ En ese gesto Ulises Bueno también se inscribe en una tradición dentro del campo. Por eso decimos que los afectos que se muestran, y el modo como se exhiben, forman parte de las apuestas discursivas. Ulises se apropia de un ritual que viene de Carlos La mona Jiménez, y que el lector puede apreciar en este vídeo: https://www.youtube.com/watch?v=2zbVCvisn3g
} 
extendió que generó una confusión: para algunos investigadores decir semiótica equivale a decir estructuralismo, inmanencia del sentido y lingüocentrismo. Este prejuicio sobre la disciplina lleva en muchos casos a despreciar de antemano los aportes tanto de otras teorías semióticas, como de la propia semiótica estructuralista.

En lo que a esta última respecta, creemos que es posible hacer una apropiación crítica de sus reflexiones, que no son pocas, acerca de las pasiones. Para hacerlo debemos tomar distancia de por lo menos dos grandes supuestos teóricos que entran en conflicto con nuestro enfoque.

En primer lugar, debemos desechar todo inmanentismo presupuesto. Como hemos dicho anteriormente, diferentes comunidades afectivas producen respuestas emocionales distintas ante las mismas músicas porque esas respuestas derivan de asociaciones de sentido socialmente producidas. Las emociones que las músicas provocan dependen, entonces, no solo de las músicas en sí mismas, ni de programaciones biológicas, sino del encuentro de esas músicas con unos intérpretes que portan saberes, competencias y asociaciones de sentido no necesariamente conscientes, acerca de esos sonidos u otros similares con los que traman analogías. ${ }^{6}$

En segundo lugar, debemos abandonar definitivamente la idea de que el significado/sentido es algo así como una "imagen mental" y que el lingüístico es el sistema de signos modelo de los demás. ${ }^{7}$ Si bien la palabra posee un innegable valor estructurante de las representaciones mentales, no es cierto que todo el sentido pueda o deba reducirse a las representaciones mentales que las palabras son capaces de producir.

Es por esto que insistimos en que el sentido que las músicas populares pueden producir en el encuentro con los intérpretes no puede inferirse de manera directa del análisis de las canciones (aun teniendo en cuenta su complejidad semiótica), ni puede limitarse a lo representacional. Sin embargo, no es menos cierto que la palabra forma parte de la canción popular y la semiótica de las pasiones ofrece herramientas valiosas para pensar el modo como esa palabra cantada pone en circulación diferentes representaciones de lo afectivo. ${ }^{8}$

\footnotetext{
${ }^{6}$ Sobre el proceso a través del cual los intérpretes producen emociones como resultado de inferencias, volveremos más adelante con mayor detalle.

${ }^{7}$ Por este motivo es preferible hablar de sentido antes que de significado, pues se trata de una diferenciación terminológica que señala una distinción teórica.

${ }^{8}$ Representaciones que podrán ser rechazadas, aceptadas o negociadas por los intérpretes en el momento de la recepción, pero que limitan un campo de efectos de sentido posibles. Cuando decimos
} 
Las canciones describen situaciones y narran historias. ${ }^{9} \mathrm{Y}$ la tesis fundacional de la semiótica de las pasiones es que en toda narración las acciones de los actores están traccionadas, se reconozca o no, por estados pasionales, entendidos éstos como cualquier estado de ánimo. Las acciones, incluso aquellas que se pretenden más "racionales", se producen porque los actores experimentan estados afectivos, que a su vez son resultado de acciones anteriores, de ellos o de otros actores. Las pasiones son, entonces, el anverso necesario de la acción. Lo pasional se convirtió, a partir de allí, en una clave de análisis ineludible a la hora de abordar los programas narrativos, y en objeto de reflexión semiótica más profunda.

Es por esto que una segunda vertiente dentro de la semiótica de las pasiones comenzó a interesarse por dar cuenta de las pasiones en sí mismas: qué pasiones desencadenan qué acciones, qué las define, qué sujetos las pueden padecer, hacia qué o quienes se dirigen, qué diferencia una pasión de otra, cómo las experimenta el actor, cómo se las valora, etc. Estos análisis, centrados fuertemente en los significados de esas pasiones, apuntaban a producir una suerte de mapa afectivo que diera cuenta de qué implica cada pasión particular, y qué la diferencia de otras. ${ }^{10}$ Qué tienen en común la codicia, la avaricia y la avidez, y qué las diferencia (Fabbri, 1995, pp. 210-215), qué es la vergüenza, cómo se manifiesta y qué acciones habilita (Marsciani, 1991), qué distingue al odio de la ira (Greimas, 1983), a la alegría de la felicidad, al amor del enamoramiento (Fabbri, 2000), a la tristeza de la nostalgia (Greimas, 1991) y a esta de la esperanza (Fabbri, 2000), etc.

Todos estos trabajos demostraron al menos tres máximas que, a nuestro entender, resultan hoy puntos de partida ineludibles:

1. Que los afectos están siempre, incluso cuando se los niega, porque son la antesala de la acción.

que el sentido se produce en el encuentro entre los enunciados y los receptores, entre las canciones y el público, y que no es ni inmanente, ni único, no quiere decir que cualquier interpretación sea igualmente válida. El objeto semiótico abre un campo de efectos posibles en una determinada cultura afectiva habilitando varias interpretaciones, pero no cualquiera (Eco, 1992).

${ }^{9} \mathrm{El}$ proyecto de la narratología estructuralista, de inspiración saussureana, fue el de construir algo así como una "lengua" del relato. Es decir, un conjunto de elementos discretos y su combinatoria. Desde las "funciones" de Propp a la "sintaxis actancial" de Greimas esa búsqueda se fue afinando. En la síntesis greimasiana las acciones narrativas son transformaciones de un estado a otro, estados que se definen por la relación de conjunción o disyunción con ciertos objetos de valor. Es justamente la relación de los actores con la adquisición, conservación o pérdida de valores lo que permite la introducción de la dimensión pasional como motivación para la acción (Greimas y Fontanille, 1994).

${ }^{10}$ Diseñaron incluso herramientas analíticas muy eficientes para examinar una a una cada pasión (Fabbri y Sbisà, 1985). 
2. Que la dimensión pasional, lejos de lo que se piensa comúnmente, no es el dominio de lo irracional y lo azaroso, sino el producto de un sistema de signos socialmente regulado que tiene sus propias lógicas. Por esto, dar cuenta de esas lógicas de producción, valoración y legitimación de las pasiones se convierte en objeto de estudio para nuestras disciplinas.

3. Todavía más, que existen axiologías pasionales (Fabbri, 1995, pp. 203220), socialmente producidas y compartidas, que establecen el valor de las distintas pasiones y, a raíz de esto, su efectividad argumentativa.

Esto último nos lleva, de manera directa, a tomar en consideración lo pasional como herramienta discursiva: son un instrumento más con el que cuenta el enunciador para influir en el enunciatario. Los afectos, su representación axiologizada en la canción popular, sirve para legitimar (o no) distintas acciones y personajes.

En el caso del análisis de las canciones, esto adquiere una relevancia evidente. En la medida en que en las canciones se narran historias, se postulan personajes y éstos se ven afectados por diversas pasiones, el análisis de la dimensión pasional es una clave analítica de gran valor para dar cuenta de aquellas regularidades discursivas que, por ejemplo, son distintivas de un determinado género o campo de producción musical.

Permite preguntarnos, por ejemplo, ¿qué emociones y sentimientos son propios del cuarteto cordobés, del trap o del folclore, y cuáles no? Y esas pasiones, ¿se conciben de la misma manera en estos diferentes campos de producción musical? ¿Se ama de la misma forma en la canción melódica que en el trap? ¿Se aman, se odian, se admiran o se recuerdan con nostalgia los mismos objetos y sujetos? ¿Cómo participa la canción popular en el mantenimiento y reproducción de determinadas axiologías pasionales? ¿Cómo se valoran esas pasiones, a qué tipo de sujetos corresponden y qué acciones desencadenan y legitiman?

Estas son algunas de las muchas preguntas que podemos hacerles a las letras de las canciones desde el análisis propiamente semiótico para avanzar, a partir de allí, hacia el análisis de las condiciones sociales que hacen posible la producción de esos discursos y no otros. 0 , en la instancia de la recepción, de las condiciones sociales que permiten que esos discursos produzcan unas emociones y no otras. En otras palabras, hacia los sistemas de valoración pasional que subyacen a esas construcciones y que son propios de distintas culturas afectivas (Le Breton, 2009). 
Observemos nuestros ejemplos a la luz de un brevísimo análisis con las herramientas que brinda la semiótica de las pasiones. Empecemos con "Amor de compra y venta". En el campo del cuarteto cordobés la aparición de un enunciador afectado por pasiones disfóricas es algo que no acontece sino hacia finales de los años 70 y se consolida en la década de $1980 .^{11}$ Es, precisamente, la emergencia de un enunciador afectado por el dolor y la tristeza uno de los elementos que señalan un cambio profundo en lo decible dentro del campo. ${ }^{12} \mathrm{Y}$ el éxito de ventas de estas nuevas propuestas son indicadores de cambios importantes en esa comunidad afectiva de la que forma parte su público, en las axiologías pasionales que a partir de allí parecen permitirles a los varones expresar dolor y sufrimiento como algo legítimo y valorado.

En ese marco es que el Cuarteto de Oro, con Carlos Jiménez como vocalista, graba "Amor de compra y venta", una canción en la que el enunciador varón se pone en la piel de un personaje que sufre. El sentimiento que se apodera del personaje es el amor, pero es un amor que genera un dolor inmenso porque ella es prostituta, y el personaje debe compartir a su amada con otros hombres. En términos narrativos, el yo lírico se encuentra en conjunción con una pasión "positiva” (el amor) pero al mismo tiempo está en conjunción con una pasión "negativa” (los celos) que le causa dolor. Este estado es resultado de una transformación desde un estado que se presenta como aún más negativo: la falta de amor. Con lo cual aparece que, en la trayectoria del sujeto, el estado de enamoramiento apasionado (aún con el dolor que acarrea) es preferible a la falta de amor/pasión ("Ella es mi gran amor/ si acaso tuviéramos que dejarnos/ sería un barco sin timón”) Él siente celos, impotencia, pero

\footnotetext{
${ }^{11}$ El cuarteto cordobés es un campo de producción musical que surge en la provincia de Córdoba (Argentina) en la década de 1940, instalándose como la música predilecta de los sectores populares de Córdoba hacia finales de la década de 1960 (Hepp, 1988). Se trataba de cuartetos característicos que amenizaban las fiestas populares tocando principalmente tarantelas y pasodobles, a los que se les imprimía una muy particular forma de marcación rítmica (Waisman, 1995), que se volvió característica distintiva de lo que se dio a llamar cuarteto cordobés. Desde entonces, el campo ha crecido y se ha consolidado, ampliando el universo de géneros que incorpora y cuartetiza, imprimiéndoles en ese gesto su marca particular. Actualmente representa la principal industria musical del interior del país, y un campo de producción musical con su propia tradición, sus instituciones consagratorias y sus formas paradigmáticas de producción musical. La música de cuarteto, en su larga vida (más de 70 años), ha atravesado profundas modificaciones que hacen difícil hablar de un género musical (motivo por el que preferimos hablar de campo de producción musical), pero mantiene al menos dos características fundamentales: Es la música de los sectores populares y es, además, una música producida para ser disfrutada en vivo y ser bailada en los numerosos "bailes" que se realizan en toda la ciudad cada fin de semana.

${ }^{12}$ Y también la aparición valorada de distintos antisujetos como, en este caso, la prostituta. Hasta entonces (año 1982) personajes hoy recurrentes en la lírica cuartetera como el preso, el marginal, la prostituta, la joven que aborta, el chico de la calle, etc.; eran extraños al cuarteto.
} 
depende tanto de ese amor que se ve obligado a aceptar lo inaceptable. Allí es posible observar cómo lo afectivo está legitimando las acciones del personaje (la aceptación de la situación, incluso la defensa de la amada ante quienes la critican).

Ahora bien, este no es un caso aislado, sino que se trata de una fórmula más o menos recurrente en el cuarteto cordobés a partir de los años 80 . El varón canta su dolor porque ama demasiado a una mujer y ese estado afectivo lo lleva, en muchos casos, a aceptar sus infidelidades y humillaciones.

Pero para comprender por qué esta es una fórmula tan recurrente, debemos salirnos de la canción y, por lo tanto, del análisis inmanente. La respuesta la encontramos en la cultura afectiva del mundo cuartetero para la cual, desde los años 80 hasta la actualidad, amar en exceso es algo que da más valor al enunciador. Existe una axiología pasional que establece qué sentimientos y emociones son valoradas y cuáles no. El amor, incluso los celos cuando son por esos amores apasionados, son sentimientos valorados, y más valorados cuanto más dolor y locura causan. Y tan así es, que en algunos casos estos estados afectivos llegan a legitimar acciones violentas, diferentes formas de violencia de género, sin que a esa comunidad afectiva le resulte cuestionable (Montes, 2019).

Lo cual nos conduce a otro punto de análisis originariamente ajeno a la semiótica de las pasiones y que es importante advertir. Las axiologías afectivas, por ser producto de relaciones sociales, están atravesadas y atravesando relaciones de poder. Vistas las cosas de esta manera, cabe preguntarse entonces por el papel que juega la canción popular en la reproducción de axiologías afectivas que funcionan como engranajes de diferentes formas de dominación social.

Tomemos ahora el ejemplo de Pimpinela, "Olvídame y pega la vuelta". Como dijimos más arriba, la emoción que predomina es la ira de la mujer ante el intento de regresar por parte del hombre que la abandonó. Y ese sentimiento de ira es lo que legitima la acción principal de la canción: el rechazo hacia el varón.

Pero este rechazo se explica porque el abandono del varón, si bien significó la pérdida de un objeto de valor de carácter pasional (el amor), implica también la adquisición de un nuevo valor que se teme perder: la autonomía ("aprendí a vivir sin tu amor"). Y la autonomía es un valor fundamental en las narrativas identitarias femeninas desde los 80 hasta ahora. Es decir, la trama narrativa de la canción se articula a su vez con una trama 
narrativa más amplia, que excede a la canción y que está ampliamente difundida en el discurso social: la historia de las complejas relaciones de varones y mujeres, de la crisis de la pareja monogámica y del ideal del amor romántico. ${ }^{13}$

Esa necesidad de salir de la inmanencia para comprender cómo ciertas estructuras narrativas "hacen sentido", nos muestra, como ya hemos dicho, que esta mirada semiótica tiene serios límites, algunos de los cuales analizaremos con más profundidad a continuación.

\section{Más allá de la palabra}

Hasta aquí hemos venido hablando del análisis de las narraciones que habitan las canciones. Sin embargo, como ya hemos dicho, las canciones son objetos semióticos complejos que involucran diferentes materialidades: palabras, melodías, ritmos, armonías, voces, etc. ¿Es posible analizar lo afectivo de la canción tomando solamente su componente lingüístico? ¿Podemos prescindir de todo lo que la música es capaz de transmitir a nivel afectivo pero que no se plasma en una imagen mental? Creemos que no.

El problema reside en que el modelo de análisis de la semiótica de las pasiones hunde sus raíces en el estructuralismo europeo y, como buena parte del conocimiento producido desde esa vertiente, está signada por un profundo linguocentrismo. ${ }^{14}$ Pero, además, es deudora de la cartesiana distinción cuerpo-mente. Anclado el modelo estructural en estas dos tradiciones, el significado es visto como algo del orden de lo "cognitivo", entendiendo esto como una imagen mental o un concepto. Todo su modelo de análisis está pensado para signos fuertemente codificados como las lenguas y se muestra incapaz de dar cuenta de los sentidos que provocan signos complejos como las músicas populares. Y esto es un problema de envergadura si de lo que queremos dar cuenta es de lo afectivo como efecto de sentido.

Consciente de estas limitaciones, Landowski (2012) ha intentado diseñar un modelo que le permita, a nuestro entender sin mucho éxito, salir de la

\footnotetext{
${ }^{13}$ En un trabajo realizado por Díaz y Argüello (2019), quedó demostrado que esta canción de Pimpinela tuvo la capacidad de interpelar masivamente al público justamente porque pudo expresar, a principios de los 80 , un malestar de las mujeres que todavía no había cristalizado en un discurso conceptual. Es decir que expresaba, siguiendo a Williams (1980), un cambio en la estructura de la sensibilidad.

${ }^{14}$ Recordemos que la semiótica estructural es hija de la lingüística.
} 
encrucijada linguocéntrica. En su propuesta distingue dos regímenes de sentido, uno del orden de lo cognitivo (aquello que es capaz de producir imágenes mentales y representaciones), y otro del orden de lo estésico, de lo corporal. La aparición de este segundo régimen de sentido también puede leerse como una reacción a ese exceso de textualismo de la etapa estructural previa y, según su propia explicación, no produce significados, sino que "hace sentido". Allí se incluirían todos esos efectos que las músicas pueden provocar a nivel de los afectos, de las sensaciones, pero que no se plasman ni pueden reducirse a representaciones.

Resulta interesante para nosotros analizar críticamente este planteo teórico porque la manera como Landowski pretende superar las limitaciones estructuralistas es común a otros enfoques contemporáneos y tiene, a nuestro entender, dos graves inconvenientes: el primero, que separando tan tajantemente los "significados" de los "sentidos", lo "cognitivo" de lo "estésico", lo afectivo de lo representacional, se sigue reproduciendo la dualidad cartesiana mente-cuerpo que tan cara ha costado a las ciencias sociales. Es un problema que comparte con una parte del "giro afectivo", que por reaccionar al exceso de textualismo termina muchas veces por reproducir la misma lógica dualista que concibe al cuerpo como reducto primitivo no socializado, no modelado, no semiotizado. Se sigue pensando la cognición como algo esencialmente consciente, racional y simbólico, y los afectos como algo inaprensible, sin lógica aparente, desvinculado de los procesos cognitivos y de las creencias de los sujetos. Es, en definitiva, la misma lógica del modelo que se pretende superar.

El segundo problema, menos evidente pero tan importante como el primero, es que genera una categoría analítica que funciona por negatividad en relación a lo lingüístico-representacional: lo estésico es todo eso que no es cognitivo/representacional, y allí ubica lo afectivo.

Es interesante detenerse en esto pues desnuda una paradoja sobre este y otros enfoques que se piensan superadores de los males del estructuralismo porque enfatizan lo corporal y lo afectivo. En la medida en que esos términos los definen por oposición (negatividad), están pensando el problema desde la lógica misma del estructuralismo. ${ }^{15} \mathrm{Y}$, en la práctica, en

\footnotetext{
${ }^{15}$ Recordemos que el modelo estructuralista concibe los problemas en términos de sistemas, en los cuales los elementos adquieren su valor por negatividad en relación a los otros elementos del propio sistema. Estos elementos, para poder definirse de esa forma, deben ser discretos. No hay lugar a continuos en el pensamiento estructural. En el plano de los sistemas de pensamiento, las teorías definen entonces sus conceptos por negatividad en relación a los otros elementos de la teoría, y al hacerlo de esa forma asumen la premisa de que esos elementos son discretos, en nuestro caso, que no habría nada corporal en la cognición ni nada de cognición en los cuerpos.
} 
lo estésico deposita todo lo que no consigue comprender o lo que, todavía peor, ha renunciado a intentar comprender. Porque si el significado es entendido como imagen mental, el "hacer sentido" no es definido en absoluto sino como todo ese resto de sentido que no puede ni definir, ni analizar.

Y deja preguntas sin intentar responder. Preguntas que nos inquietan, que nos resultan imprescindibles: ¿Cómo es que una música puede "hacer sentido"? ¿Por qué provoca esas emociones y no otras? ¿De dónde vienen esas respuestas afectivas que provoca? ¿Se trata de reacciones corporales/ afectivas no mediadas por cognición alguna? Si damos esto último por cierto, entonces estamos asumiendo que se trata de afectos reflejos (como el reflejo de Moro), y por lo tanto universales e innatos. Sin embargo, a donde quiera que miramos encontramos músicas que provocan emociones diferentes en distintos grupos de sujetos.

Si regresamos al ejemplo de "Amor de compra y venta", en la versión de Ulises Bueno, ¿cómo podemos comprender la emoción que transmite más allá de lo que dice la letra? Pensamos que buena parte de la respuesta afectiva que genera en su público depende de su particular manera de vocalizar. El lector de este trabajo tal vez piense que Ulises Bueno canta mal, y se esté preguntando qué emoción le produce escucharlo. Es posible que arribe a la conclusión de que le produce desagrado escuchar a alguien cantar con tanto desprecio por la afinación y la calidad vocal. Si es así, le sorprenderá saber que, para el público cuartetero, Ulises canta como debe hacerlo un verdadero cuartetero, porque transmite "sentimiento" con su voz. Con la voz en la garganta, a veces gritando o carraspeando, como si la voz fuera metáfora del alma, Ulises Bueno canta "desgarrando" la voz y, en ese sonido, consigue transmitir (según la mirada cuartetera) ese dolor que desgarra el alma. Ese sentido, esa emoción que se "contagia", es posible porque esa manera particular de vocalizar es ya un rasgo distintivo de buena parte del cuarteto cordobés. Una manera de cantar que impuso La mona Jiménez y que esta comunidad afectiva denomina "cantar con sentimiento". Es decir, es una convención, pero una convención ya incorporada al habitus (Bourdieu, 1999). Por eso al público ulisero lo estremece más la canción cuando él la canta así, carraspeando, gritando, sufriéndola. Esa forma de vocalizar produce sentido, aunque no sea un significado en términos de representaciones. Produce sentido porque transmite un estado afectivo del cantante, acompañando y reforzando lo que dice la letra. Aunque no sea consciente, hay un proceso cognitivo en la emoción que esa vocalización provoca. La emoción es resultado de todas esas creencias y juicios previos. 
En el caso de "Olvídame y pega la vuelta”, del Dúo Pimpinela, buena parte del efecto emotivo que genera depende de la articulación entre la historia narrada y algunos rasgos musicales y performáticos. Es necesario recordar que las "canciones de pelea" de Pimpinela, a diferencia de otros duetos (Party y Kalawsky, 2020) consisten en la dramatización de dos personajes en pleno conflicto. La armonización, los giros melódicos, la orquestación y la interpretación vocal van acompañando el desarrollo de la historia narrada. Así, en la primera estrofa, cuando la mujer narra su historia en un soliloquio, el acompañamiento instrumental es mínimo y la voz es casi un susurro. En contraste, cuando el varón regresa y reclama una explicación al rechazo, aumenta la intensidad y se usa la parte más aguda del registro. De ese modo en el estribillo se "pone en escena" la ira sin necesidad de nombrarla. No porque necesariamente esos rasgos sonoros estén asociados a la ira, sino porque se ajustan perfectamente a regulaciones sociales preexistentes que nos hacen saber que cuando alguien está enojado tiende a "levantar la voz". Aquí la voz se "eleva" tanto por la línea melódica como por la intensidad. Y la gestualidad en escena refuerza el mismo efecto.

Así pues, aunque las emociones, la respuesta afectiva que las canciones generan, no puedan ser reducidas a una "imagen mental" o a un concepto, eso no significa que estén menos mediadas socialmente, ni que el análisis de los medios por los que se provoca esa respuesta emotiva sea imposible.

\section{El sentido como efecto: más allá de la letra y de la música}

Otro paradigma semiótico ofrece un modelo distinto para pensar lo afectivo. Para la semiótica peirceana el significado de un signo no está definido de antemano como una imagen mental ni como una representación. El sentido de un signo es su efecto y este puede, o no, tomar una forma simbólica. Esto quiere decir que si una música provoca sensaciones que no somos capaces de poner en palabras, eso no significa que esa música no tenga un significado. Su significado es, precisamente, esas sensaciones que provoca.

Todavía más, supone que todo signo, para ser tal, debe primero afectarnos, golpearnos, generar en el intérprete algún estado afectivo que lo movilice a generar, eventualmente, una representación mental de eso que lo afecta. Parte del supuesto de que los seres humanos no convivimos bien con la duda y que nuestra tendencia natural es a establecer creencias. Por este motivo, cuando nos enfrentamos a cualquier paquete significante, nuestra mente busca de manera espontánea darle un significado, una "imagen 
mental" si utilizáramos la terminología estructuralista. Ese encuentro del sujeto con ese paquete significante genera un estado (afectivo) de insatisfacción por la ausencia de significado, que moviliza al sujeto a realizar distintas inferencias para fijar una idea sobre eso que lo afecta. Dicho en otras palabras, nos es difícil de tolerar la ausencia de significado, de modo que ese estado de afectación es el que nos empuja a buscarle el sentido a todo con lo que tenemos contacto.

Desde esta perspectiva, entonces, no habría signos que afectan emocionalmente y signos que tienen un significado en términos representacionales, sino que lo afectivo se concibe como una dimensión de todo proceso de producción de sentido, incluidas las representaciones mentales. La diferencia no es pequeña. Mientras en otras corrientes se piensa a lo afectivo como opuesto a lo representacional, aquí se lo piensa como diferentes momentos de un mismo proceso: la semiosis.

Aún más, la distinción mental-corporal pierde relevancia para este paradigma porque lo mental es concebido in corpore. Se trata de una mente extendida (Paolucci, 2011), de una cognición encarnada (López Cano, 2005 y 2011), de una perspectiva que se opone al dualismo cartesiano.

La diferencia crucial con el paradigma estructural es que para el paradigma peirceano, lo afectivo es entonces parte de cualquier proceso de significación. Es, en realidad, el primer paso de un proceso que puede conducir, o no, al establecimiento de una representación.

Todo signo provoca en el intérprete alguna sensación, lo afecta de una manera que es al mismo tiempo mental y corporal. Esta afectación lo moviliza a buscar lo que Peirce (1931-1958) llama un interpretante lógico, es decir una idea, una hipótesis acerca de lo que es eso que lo está afectando. Esta idea es un paso lógicamente posterior, al que se puede, o no, arribar. Como el propio Peirce lo señala, algunos signos no consiguen desarrollar ese grado de significación. Es más, a veces esas sensaciones primeras son el único efecto verdaderamente significativo para esos signos. Y cuando explica esto, lo ejemplifica, precisamente, con la música (CP 5.475). ${ }^{16}$

Vistas las cosas de esta manera, los efectos emocionales que los signos son capaces de provocar no requieren un modelo explicativo distinto

\footnotetext{
${ }^{16}$ La referencia a la obra de Peirce se realiza de acuerdo a la usanza internacional, donde CP significa Collected Papers, el primer dígito corresponde al volumen y detrás del punto se consigna el número de párrafo.
} 
del que es válido para cualquier otro tipo de signo. Nos emocionamos a través de los mismos procesos cognitivos con los que interpretamos las señales de tránsito, un libro, o una noticia periodística. Lo que cambia es el tipo de afectación y la intensidad con la que la experimentamos, siendo mucho más importantes en estos signos que llamamos emociones (Montes, 2016).

Esos procesos cognitivos se fundan en las creencias previas de los sujetos y en las inferencias que son capaces de realizar a partir de éstas. Las emociones, pues, no ocurren por magia, por contagio de los cuerpos o por una programación innata.

Nos emocionamos cuando escuchamos una canción porque somos capaces de empatizar con su enunciador, porque lo hemos juzgado previamente como equivalente a nosotros. Nos emocionamos porque elaboramos un juicio sobre eso que percibimos, y ese juicio depende de las creencias que hemos incorporado a lo largo de la socialización y que operan como premisas tácitas de los procesos inferenciales que conducen a la emoción.

Podremos pensar, siguiendo a Bourdieu (1999), que esas premisas tácitas operan desde el habitus. Son creencias hechas cuerpo, esquemas de percepción, valoración y acción que revelan tanto la posición que ocupamos en el espacio social como la trayectoria. Que no sean necesariamente conscientes, que no puedan traducirse en palabras ni en representaciones conceptuales no significan que no sean socialmente producidos y, por lo tanto, parte de la semiosis social.

Nuestro corazón late con fuerza y la euforia nos invade el cuerpo cuando cantamos en la hinchada viendo un partido de fútbol porque primero hemos establecido todo un conjunto de creencias acerca de la importancia de ese evento, de su lugar en la construcción simbólica de nuestra identidad, incluso sobre la existencia de una suerte de comunidad a la cual creemos pertenecer y a la cual esa canción al mismo tiempo expresa y contribuye a producir. Todas esas creencias, y tantas otras, son las que permiten comprender por qué nos emocionamos como lo hacemos al alentar a nuestro equipo. Y la mayor prueba del carácter cognitivo y social de la emoción, es que no sentimos lo mismo si cantamos las mismas canciones, pero en la hinchada contraria. No son las músicas en sí mismas, sino todos los significados que hemos depositado previamente, todas las creencias anteriores a partir de las cuales producimos significados nuevos, las que explican los efectos emotivos que provocan. 
Concebir los efectos emocionales de esta forma tiene consecuencias importantísimas y marca profundas distancias tanto con la mirada estructural, como con toda la tradición del pensamiento cartesiano. Por una parte, nos permite salir del callejón sin salida en el que nos ubican las falsas dicotomías mente/cuerpo, cognición/emoción, significado/sentido, etc. Por otra, nos da herramientas para comprender por qué unas músicas producen diferentes emociones en distintos grupos de sujetos.

\section{Reflexiones finales. Músicas populares, cognición, afectos e interpelación}

Al comenzar este trabajo nos propusimos rescatar algunos aportes de tradiciones teóricas de la sociología y de la semiótica que nos permiten pensar lo afectivo/emocional en la música popular, sin caer en lo que consideramos una exagerada, y cuestionable, separación de lo afectivo y lo cognitivo.

Los trabajos agrupados en el denominado "giro afectivo", tienen el mérito de reconocer la relevancia de los aspectos emocionales en la construcción de modelos explicativos de las prácticas sociales, entre ellas la producción y consumo de músicas populares. Sin embargo, hemos observado que a veces se asientan en una suerte de dualismo inverso: Por enfatizar la importancia de lo afectivo, corporal y no representacional, olvidado por mucho tiempo en favor de lo racional, mental y "cognitivo", terminan por reproducir la misma lógica de separación entre estos términos, que no es otra que la del dualismo cartesiano y la de la negatividad estructuralista.

Como consecuencia, el ámbito de los afectos no encuentra herramientas analíticas que permitan dar cuenta de su funcionamiento. Porque si lo afectivo es radicalmente opuesto a lo representacional/cognitivo, entonces no puede regirse por lógicas o procesos análogos, ni abordarse con similares herramientas.

Pero si revisamos esa manera de concebir lo afectivo, si en lugar de considerarlos procesos mutuamente excluyentes los entendemos como diferentes dimensiones, siempre presentes, de los fenómenos sociales, entonces descubrimos que las pasiones tienen sus propias razones. Si evitamos poner la dimensión afectiva/emocional de las músicas populares en el lugar de lo inmediato, de lo pre-semiótico y pre-social, podemos intentar dotarnos de las herramientas analíticas necesarias para abordar esa dimensión en su complejidad. Si asumimos que las emociones son el 
resultado de procesos cognitivos que involucran creencias y saberes previos hechos cuerpo, en definitiva un habitus; que no son procesos individuales sino que existen lógicas afectivas que operan en grupos de sujetos que comparten trayectorias similares en el espacio social, y que tanto su producción como su expresión está socialmente reguladas; entonces es posible intentar dar cuenta de sus lógicas, incluyendo la capacidad de ciertas músicas para interpelar a ciertos sujetos y contribuir a la construcción de identidades sociales.

Nuestra propuesta, entonces, consiste en incorporar la acentuación de lo afectivo/emotivo en el análisis de las músicas populares, pero recuperando críticamente los aportes de tradiciones de pensamiento que no deberían ser desechadas sin más, como la sociología del cuerpo y las emociones, la semiótica de las pasiones y el paradigma semiótico periciano. Esto es, los fundamentos teóricos que han permitido el desarrollo de la sólida tradición disciplinar de los estudios del discurso que, desde nuestro punto de vista, todavía tiene mucho que aportar para la comprensión de estas músicas que tanto apasionan. 


\section{Bibliografía}

»Arfuch, L. (2016). El "giro afectivo". Emociones, subjetividad y política. DeSignis. Emociones en la nueva esfera pública, 24, 245-254.

»Bourdieu, P. (1999). Meditaciones pascalianas. Barcelona: Anagrama.

»De Rugemont, D. (1959). El amor y occidente. Buenos Aires: Ed. Sur.

»Díaz, C. y Argüello, S. (2019). El Dúo Pimpinela y el malestar de las mujeres. Dimensión pasional, dispositivo de enunciación y sentido en la música popular. Ponencia presentada en el 14º Congreso Mundial de Semiótica. Buenos Aires. Inédita.

»Eco, U. (1992). Los límites de la interpretación. Barcelona: Lumen.

»Elias, N. (2011). El proceso de la civilización. Investigaciones sociogenéticas y psicogenéticas. México: Fondo de Cultura Económica.

» Fabbri, P. (1995). Tácticas de los signos. Barcelona: Gedisa.

»Fabbri, P. (2000). El giro semiótico. Barcelona: Gedisa.

» Fabbri, P. e Sbisà, M. (1985). Appunti per una semiotica delle passioni. En Aut-Aut, 208, pp. 101-118. Recuperado de: http://www.paolofabbri.it/saggi/ appunti_semiotica_passioni.html

»Frith, S. (2003). Música e identidad. En S. Hall y P. Du Gay (Eds.). Cuestiones de identidad cultural (pp. 181-213). Buenos Aires: Amorrortu.

» Goffman, E. (1997). La presentación de la persona en la vida cotidiana. Buenos Aires: Amorrortu Editores.

» Greimas, A. (1983). De la cólera. Estudio de semántica léxica. En Del sentido II (pp. 255-280). Madrid: Gredos.

»Greimas, A. (1991). Della nostalgia. Studio di semántica lessicale. En I. Pezzini. Semiotica delle passioni. Saggi di analisi semántica e testuale (pp. 1926). Bologna: Esculapio.

» Greimas, A. y Fontanille, J. (1994). Semiótica de las pasiones. De los estados de cosas a los estados de ánimo. Puebla: Siglo XXI editores.

" Guiddens, A. (2008). La transformación de la intimidad. Sexualidad, amor y erotismo en las sociedades modernas. Madrid: Cátedra.

» Hepp, O. (1988). La soledad de los cuartetos. Córdoba: Edición del autor.

»Landowski, E. (2012). ¿Habría que rehacer la semiótica?. En Contratexto, 20, 127-155.

» Lara, A. y Enciso Domínguez, G. (2013). El giro afectivo. Athenea Digital, 13(3), 101-119.

» Le Breton, D. (1998). Antropología del cuerpo y modernidad. Buenos Aires: Nueva Visión.

»Le Breton, D. (2009). Las pasiones ordinarias. Antropología de las emociones. Buenos Aires: Nueva Visión. 
» López Cano, R. (2005). Los cuerpos de la música. Introducción al dossier Música, cuerpo y cognición, en revista TRANScultural de música, 9. Recuperado de: http://www.sibetrans.com/trans/a175/los-cuerpos-de-lamusica-introduccion-al-dossier-musica-cuerpo-y-cognicion

» López Cano, R. (2011). Música, mente y cuerpo. De la semiótica de la representación a una semiología de la performatividad. En M. Fornaro (Ed.): De cerca, de lejos. Miradas actuales en musicología de/sobre América Latina. Montevideo: Universidad de la República. En prensa. Recuperado de: http:// lopezcano.org/Articulos/2011.perform.pdf

»Luci Pereira, S. (2016). Matrizes e mediações das canções românticas na América Latina. En M. Tupinambá de Ulhôa y S. Luci Pereira (Eds.). Canção romântica. Intimidade, mediação e identidade na América Latina (pp 25-47). Río de Janeiro: Folio Digital.

»Marsciani, F. (1991). Uno sguardo semiótico sulla vergogna. En I. Pezzini. Semiotica delle passioni. Saggi di analisi semántica e testuale (pp. 35-50). Bologna: Esculapio.

»Montes, M. de los A. (2016). De la semiótica de las pasiones a las emociones como efectos: la dimensión afectiva vista desde una mirada pragmatista. Linguagem em (Dis)curso, 16(1). doi: http://dx.doi.or g/10.1590/1982-4017-160110-4115

»Montes, M. de los A. (2019). Masculinidades, pasión y violencia en las letras del cuarteto cordobés (1976-1990). En Contrapulso, 1/1. Recuperado de https://contrapulso.uahurtado.cl/index.php/cp/article/view/6/6

»Paolucci, C. (2011). The "External Mind": Semiotics, Pragmatism, Extended Mind and Distributed Cognition. En VS Quaderni di studi semiotici, Gennaiodicembre 2011. Kindle Edition.

»Party, D. y Kalawsky, A. (2020). Escenas contra la soledad: el diálogo en los duetos pop. Contrapulso. Revista latinoamericana de estudios en música popular, 2(1). Recuperado de https://contrapulso.uahurtado.cl/index.php/ cp/article/view/16/15

»Peirce, C. S. (1931-1958). A Survey of Pragmaticism. En Hartshorne, Weiss \& Burks (Eds.), Collected Papers. Cambridge, Ma: Harvard University Press.

» Ricoeur, P. (1996). Tiempo y Narración III. El tiempo narrado. México, Madrid: Siglo XXI.

»Segato, R. (2003). Las estructuras elementales de la violencia. Bernal: Universidad Nacional de Quilmes.

»Verón, E. (1996). La semiosis social. Fragmentos de una teoría de la discursividad. Barcelona: Gedisa.

»Vila, P. (2017). Music, Dance, Affect, and Emotions: Where We Are Now. En P. Vila (Ed.). Music, Dance, Affect, and Emotions in Latin America (pp. 1-39). Lanham, Boulder, New York, London: Lexinton Books.

»Vila, P. y Molinero, C. (2017). Cantando los afectos militantes. Las emociones 
y los afectos en dos obras del canto folklórico peronista y marxista de los 70.

Buenos Aires: Academia Nacional de Folklore.

»Waisman, L. (1995). Tradición, innovación e ideología en el cuarteto cordobés. En Actas de las VIII Jornadas argentinas de musicología (pp. 122-

146). Buenos Aires: Instituto Nacional de Musicología Carlos Vega.

»Williams, R. (1980). Marxismo y literatura. Barcelona: Península.

\section{Biografías / Biografias / Biographies}

\section{Claudio F. Díaz}

Magíster en Sociosemiótica y Doctor en Letras por la Universidad Nacional de Córdoba. Es docente de la cátedra de Sociología del Discurso en la Facultad de Filosofía y Humanidades de dicha universidad. Dirige un equipo de investigación radicado en el Centro de Investigaciones de la FFyH, centrado en los estudios sobre músicas populares. Se ha desempeñado como Director de dicho Centro, como así también de la Escuela de Letras de esa Facultad. Ha publicado artículos en revistas especializadas y es autor de Libro de viajes y extravíos. Un recorrido por el rock argentino (19651985) (Narvaja Editor, 2005), y de Variaciones sobre el "ser nacional". Una aproximación sociodiscursiva al "folklore" argentino (Ediciones Recovecos, 2009), y es miembro fundador de la Rama Latinoamericana de la IASPM.

\section{María de los Ángeles Montes}

Doctora en Semiótica por la Universidad Nacional de Córdoba. Es investigadora del Consejo Nacional de Investigaciones Científicas y Técnicas (CONICET) y docente de la Universidad Provincial del Córdoba (UPC). Actualmente forma parte de un equipo de investigación radicado en Instituto de Humanidades de la UNC, abocado al estudio de la dimensión emocional de las músicas populares. Sus investigaciones se han centrado principalmente en los procesos de recepción musical y, más recientemente, en el campo de producción del cuarteto cordobés. Ha publicado trabajos en revistas especializadas tanto nacionales como extranjeras. 